Article

\title{
Construction of an Ultrasensitive and Highly Selective Nitrite Sensor Using Piroxicam-Derived Copper Oxide Nanostructures
}

\author{
Ali Alsalme ${ }^{1}$, Munazza Arain ${ }^{2}$, Ayman Nafady 1,3,* and Sirajuddin 4,* \\ 1 Department of Chemistry, College of Science, King Saud University, P.O. Box 2455, \\ Riyadh 11451, Saudi Arabia; aalsalme@ksu.edu.sa \\ 2 Dr. M. A. Kazi Institute of Chemistry, University of Sindh, Jamshoro 76080, Pakistan; \\ munazzaarain2493@gmail.com \\ 3 Chemistry Department, Faculty of Science, Sohag University, Sohag 82524, Egypt \\ 4 National Center of Excellence in Analytical Chemistry, University of Sindh, Jamshoro 76080, Pakistan \\ * Correspondence: anafady@ksu.edu.sa (A.N.); drsiraj03@yahoo.com (S.); Tel.: +966-56-940-7110 (A.N.); \\ +92-336-305-1253 (S.)
}

Received: 11 December 2017; Accepted: 12 January 2018; Published: 17 January 2018

\begin{abstract}
In this work, piroxicam-based copper oxide nanostructures (Px-CuO NSs) were synthesized via hydrothermal precipitation in the presence of ammonia. The prepared $\mathrm{Px}-\mathrm{CuO}$ NSs were subjected to scanning electron microscopy (SEM) and X-ray diffraction (XRD) to obtain morphology and crystallinity, respectively. The SEM study reveals that these Px-CuO NSs are in the form of porous rose-like nanopetals with dotted particles on their surface, while the XRD study confirms their crystalline nature. The Px-CuO NS-based sensors were fabricated by drop-casting them onto the surface of a glassy carbon electrode (GCE) and they were tested for nitrite detection using voltammetry and amperometry. The results show these Px-CuO NSs to be highly stable on the GCE surface with linear amperometric (current vs. time) responses to wide range of nitrite concentrations from 100 to $1800 \mathrm{nM}$, with limits of detection (LOD) and quantification (LOQ) being $12 \mathrm{nM}$ and $40 \mathrm{nM}$, respectively. Importantly, the fabricated sensor showed negligible effects for a 10-fold higher concentration of common interfering agents and exhibited excellent selectivity. It was applied successfully for nitrite detection in water samples such as river water, mineral water, and tap water.
\end{abstract}

Keywords: piroxicam; copper oxide nanostructures; amperometric sensor; nitrite; water samples

\section{Introduction}

Nitrite ions have great ecological importance because they are involved as intermediates in the nitrogen cycle [1,2] and are widely utilized as preservatives in foods and soils, for lowering hypertension, and as vasodilators [3]. Despite these useful applications, nitrites form carcinogenic nitrosamines when combined with secondary amines in the body [3]. Due to this toxic aspect, it is essential to monitor the level of nitrites, especially in samples that cause environmental and health concerns [1,4].

Nitrites have been detected using several sophisticated techniques such as chemiluminescence [5], spectrofluorimetry [2], capillary electrophoresis [6], chromatography [7], and electroanalysis [8]. Among these, the electroanalytical methods are considered more efficient due to lower cost, portable instruments, simpler set-up, ease of sample preparation and processing, and higher sensitivity/selectivity $[9,10]$. These characteristics make electroanalysis the method of choice for many diagnostic studies.

Metal oxide nanostructures are associated with several catalytic properties and are implemented to significantly improve electron-transfer processes with different types of solid electrodes designed 
for detection of various analytes [11-13]. Among metal oxide nanostructures, $\mathrm{CuO}-\mathrm{NSs}$ have been the focus of interest in sensor development due to their low cost, ease of preparation at relatively low temperatures, high stability and catalytic activity, and hence, rapid electron transfer kinetics. In this respect, $\mathrm{CuO}$ nanoparticles (NPs) incorporated onto various membranes have been utilized for sensing a wide range of important chemicals such as $\mathrm{H}_{2} \mathrm{~S}$ [14], dopamine [15], pesticide [16], carbamates [11], and NO [17].

Previously, nitrite ions have been detected using electrodes modified with metal oxide NPs, including cobalt oxide NPs [18,19], ferric oxide $\left(\mathrm{Fe}_{3} \mathrm{O}_{4}\right)$ nanospheres [20], and ferrous oxide $\left(\mathrm{Fe}_{2} \mathrm{O}_{3}\right)$ NPs [21]. Although the determination of nitrite via $\mathrm{CuO}$ has seldom been studied, it is worth mentioning the report by Zhang et al. [22] who casted hexamethylenetetramine-based $\mathrm{CuO}$ nanoflowers on the active surface of a GCE for the sensitive detection of hydrogen peroxide $\left(\mathrm{H}_{2} \mathrm{O}_{2}\right)$ and nitrites.

In this contribution, we describe a facile procedure to synthesize piroxicam (Figure 1) based copper oxide nanostructures (Px-CuO NSs) via a hydrothermal method at low temperature $\left(95^{\circ} \mathrm{C}\right)$ in the presence of ammonia. The as-prepared Px-CuO-NSs were successfully fabricated onto GCEs and employed as electrochemical sensors for highly selective and sensitive detection of nitrites. Importantly, the fabricated nitrite sensor was further utilized for nitrite determination in real water samples with an acceptable range of recovery.<smiles>CN1C(C(=O)Nc2ccccn2)=C(O)c2ccccc2S1(=O)=O</smiles>

Figure 1. The structure of piroxicam (Px).

\section{Results and Discussion}

\subsection{Characterization of As-Prepared $\mathrm{Px}$-CuO NSs}

\subsubsection{SEM Study}

Px-CuO NSs were characterized by SEM and XRD to gain information about their morphology, crystal size, and crystalline nature. SEM images of the Px-CuO NSs are illustrated in Figure 2, with (a) depicting a low-magnification image and (b) a high-magnification image of the $\mathrm{CuO}$ NS structure.
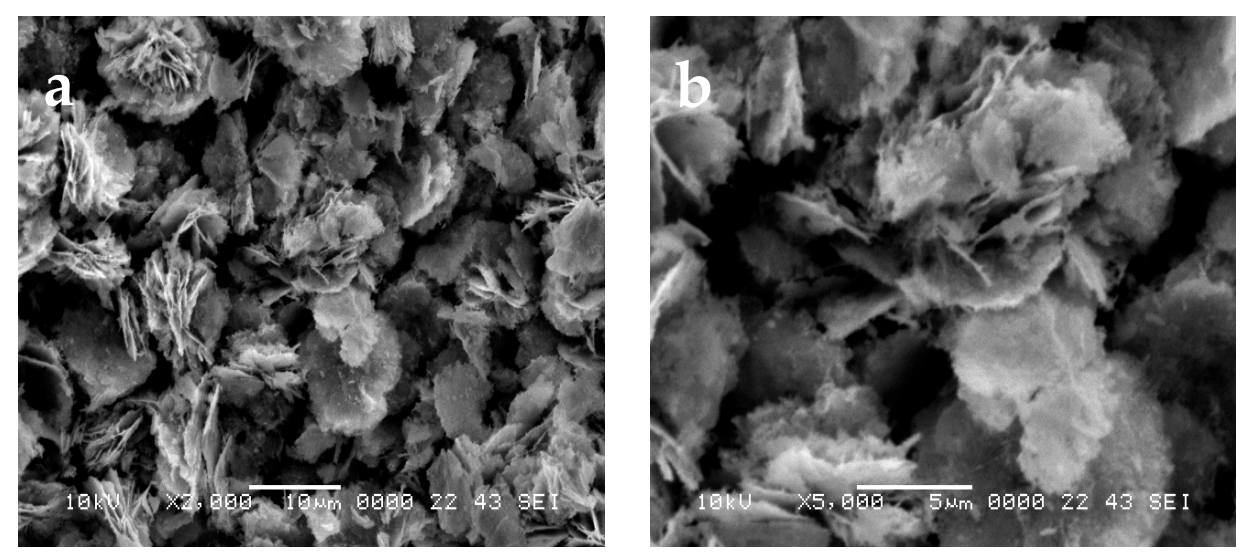

Figure 2. SEM images of Px-CuO NSs (a) with low magnification, (b) with high magnification. 
The images clearly show that these nanostructures are composed of many nanoflakes with porous rose-petal-like morphology with some dotted particles deposited over the petals, which are essential for the high catalytic and enhanced electron-transfer reaction associated with nitrite oxidation at modified GCEs.

\subsubsection{XRD Study}

Figure 3 illustrates various crystalline patterns associated with Px-CuO NSs. These patterns typically describe face-centered cubic (fcc) crystal lattice structures and confirm that most of the $\mathrm{CuO}$ product exhibits these facets.

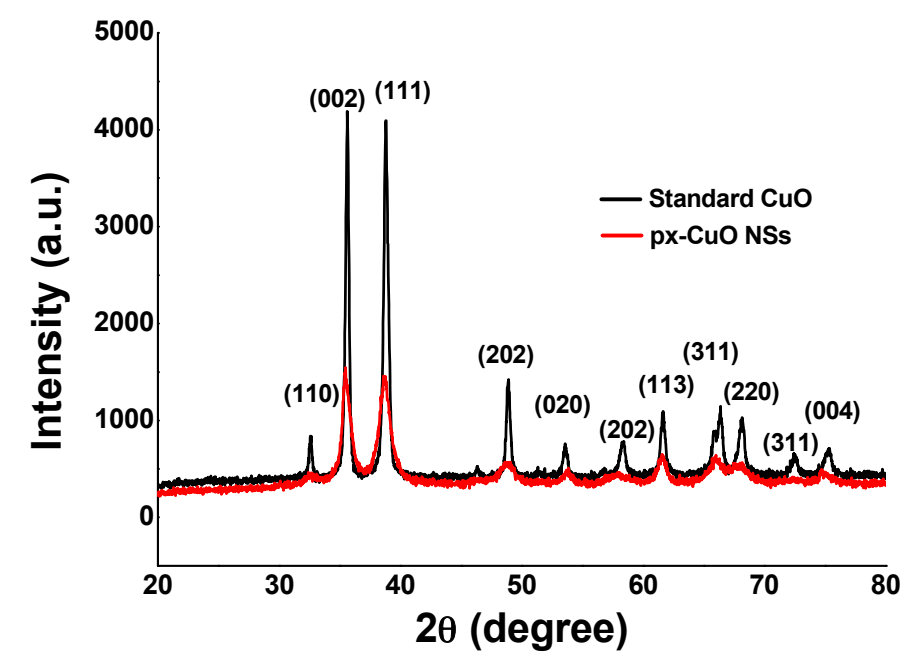

Figure 3. XRD crystalline patterns of Px-CuO NSs (red) and standard $\mathrm{CuO}$ (black).

Importantly, all the crystalline facets of the Px-CuO NSs (patterns in red) and the respective angles clearly match the standard $\mathrm{CuO}$ compound patterns (in black), thereby confirming the pure formation of only one crystalline polymorph of $\mathrm{CuO}$ structure.

\subsection{Sensing Studies}

\subsubsection{Sensitivity Investigation}

Figure 4 demonstrates the sensitivity of the Px-CuO NSs modified GCE (Figure 4d) as compared to the bare GCE (Figure 4c) for $1 \mathrm{mM}$ nitrite detection based on the change in peak current. The figure also depicts the response of blank solution for bare GCE (Figure 4a) and Px-CuO NS-modified GCE (Figure $4 \mathrm{~b}$ ). It is clearly observed that the bare GCE does not show any prominent peaks for $1 \mathrm{mM}$ nitrite oxidation whereas a high catalytic current peak is observed when the Px-CuO NSs-modified GCE is used. Qualitatively, the obtained results are in good agreement with those reported earlier [22] by Zhang et al. who also used flower-like copper oxide for hydrogen peroxide and nitrite sensing using phosphate buffer at $\mathrm{pH}$ 7.0. These results clearly attest that $\mathrm{Px}-\mathrm{CuO}$ NSs provide the active sites responsible for the enhanced electrocatalytic oxidation of $\mathrm{NO}_{2}{ }^{-}$as described by the following equations

$$
\begin{gathered}
2 \mathrm{NO}_{2}^{-} \leftrightarrow 2 \mathrm{NO}_{2}+2 e^{-} \\
2 \mathrm{NO}_{2}+\mathrm{H}_{2} \mathrm{O} \rightarrow \mathrm{NO}_{3}^{-}+\mathrm{NO}_{2}^{-}+2 \mathrm{H}^{+} \\
\mathrm{NO}_{2}^{-}+\mathrm{H}_{2} \mathrm{O} \rightarrow \mathrm{NO}_{3}^{-}+2 \mathrm{H}^{+}+2 e^{-}
\end{gathered}
$$




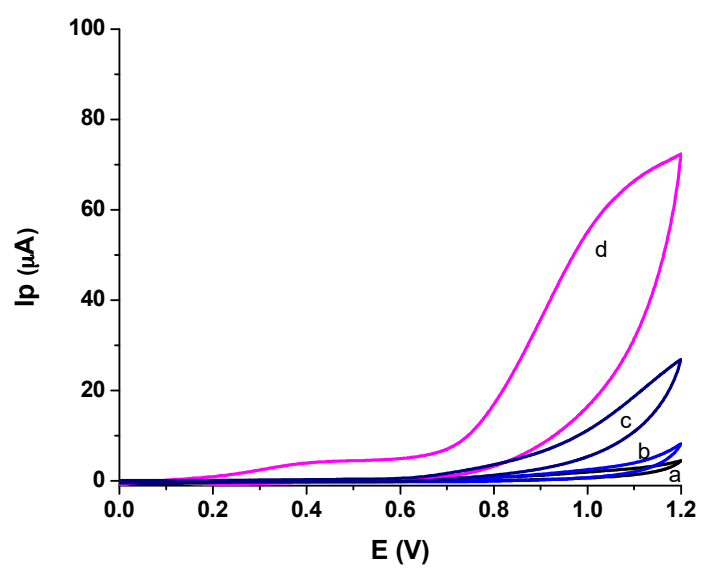

Figure 4. Cyclic voltammograms obtained for $1 \mathrm{mM}$ nitrite solution in phosphate buffer (pH 7.0) and scan rate of $100 \mathrm{mV} \mathrm{s}^{-1}$ using (d) Px-CuO NSs-modified GCE and (c) bare GCE. Curves (a) and (b) are the $\mathrm{CV}$ responses of the blank solution (phosphate buffer, $\mathrm{pH}$ 7.0) using bare and Px-CuO NS-modified GCE, respectively.

Virtually, our Px-CuO NS-based sensor is about four times more sensitive for nitrite detection than the analogous $\mathrm{CuO}$ sensor developed by Zhang et al. [22]. These significant enhancements in peak current and peak potential are most likely due to differences in morphology and shape-directing agents. We also determined the geometric area of Px-CuO NS-modified electrode as per procedure described elsewhere [23] and it was $0.067 \mathrm{~cm}^{2}$.

\subsubsection{Effect of Scan Rate}

Figure 5 illustrates cyclic voltammograms (CV) obtained with the Px-CuO NSs-modified GCE for $1 \mathrm{mM}$ nitrite solution as a function of scan rate over the range $50-900 \mathrm{mV} \cdot \mathrm{s}^{-1}$. The inset shows the linear response of the current values with the square root of the scan rates, with an $R^{2}$ value of 0.992 . The linear behavior of the plot suggests that the oxidation of nitrite into nitrate is purely diffusion-controlled.

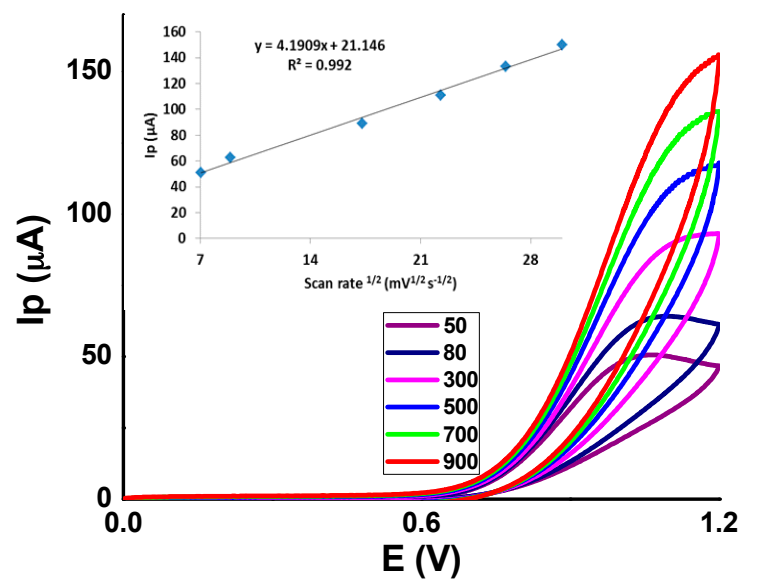

Figure 5. CVs showing the effect of scan rates on peak current values of $1 \mathrm{mM}$ nitrite solution in phosphate buffer at pH 7.0 using Px-CuO NSs-modified GCE: the inset depicts the dependence of peak current values on the square root values of the scan rates.

A similar behavior has previously been observed for nitrite oxidation at $\mathrm{Fe}_{3} \mathrm{O}_{4}$ nanospheres [20]. However, experimental aspects such as buffer solution, $\mathrm{pH}$ values, and electrode material could be the differentiating factors between the two results. 


\subsubsection{Calibration}

The sensing trend of Px-CuO NS-modified GCE with changing nitrite concentration was first studied using a calibration curve in the CV mode. Figure 6 shows this behavior with the inset showing the corresponding calibration plot. The results in the inset figure clearly establish that linear dependence is evident only at higher nitrite concentrations and slightly deviates from linearity at lower concentration of nitrites. Similarly, the magnitude of $\left(R^{2}=0.9758\right)$ implies that the sensor does not behave very well when used in CV mode.

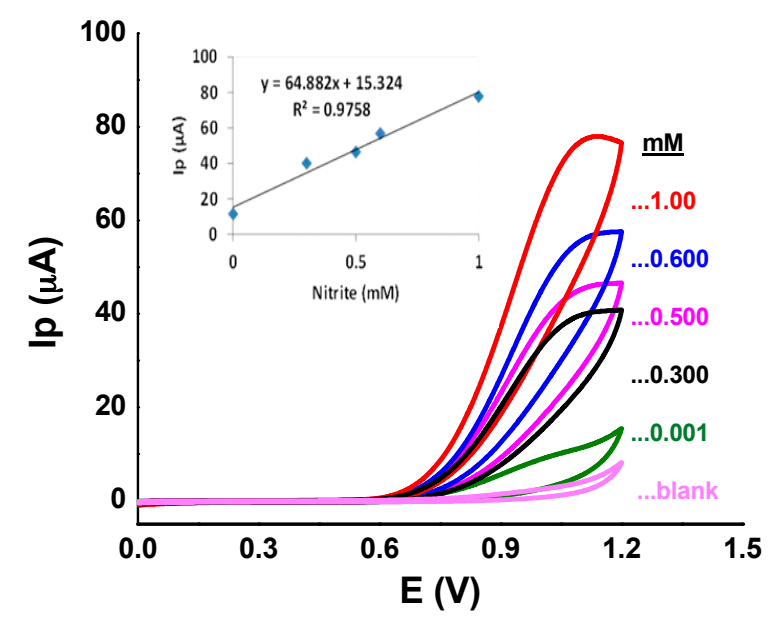

Figure 6. CVs obtained with the Px-CuO NSs-modified GCE and scan rate of $100 \mathrm{mV} \mathrm{s}^{-1}$ in phosphate buffer ( $\mathrm{pH} 7.0$ ), illustrating the change in peak current as a function of nitrite concentration over the range $0.001-1.0 \mathrm{mM}$. The inset shows the corresponding linear plot.

\subsubsection{Reproducibility and Long-Term Stability}

To evaluate the practical usage of the developed Px-CuO NS-modified-GCE for several runs, the reproducibility of a single modified electrode was checked for five repetitive CVs in $0.5 \mathrm{mM}$ nitrite solution as shown in Figure 7. The calculated data provided a relative standard deviation of $0.2 \%$ which verifies the high reproducibility and repeatability of the developed electrode. Furthermore, the long-term stability was studied over one month twice per week for Px-CuO NS-modified GCE and the results showed a relative standard deviation of $2.1 \%$ (data not shown) which confirms good long-term stability for the newly developed electrode. Indeed, the reproducibility and long-term stability play crucial roles in the economics of the modified electrode.

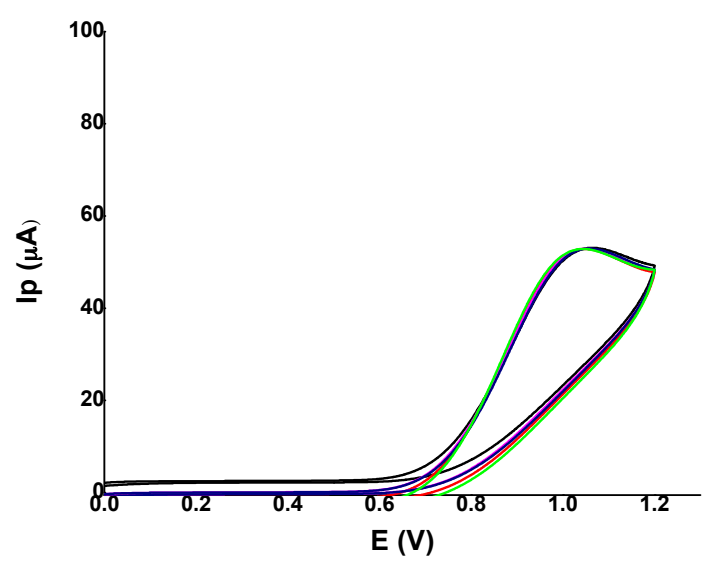

Figure 7. Five repetitive CVs for Px-CuO NS-modified GCE in $0.5 \mathrm{mM}$ nitrite in phosphate buffer $(\mathrm{pH}, 7.0)$ using scan rate of $100 \mathrm{mV} \mathrm{s}^{-1}$. 


\subsection{Amperometric Study}

\subsubsection{Amperometric Calibration}

The Px-CuO NS-modified GCE was also calibrated using amperometric (peak current versus time) responses. Figure 8 shows the obtained amperometric curve for nitrite in the range 100-1800 nM. The corresponding inset plot shows an $\mathrm{R}^{2}$ value of 0.9951 with LOD of $12 \mathrm{nM}$ and LOQ of $40 \mathrm{nM}$. The LOD and LOQ values were determined by the methods reported previously $[9,24]$. Although the electrode was checked for 100-3600 nM nitrite concentration and was giving good results but the former range was producing the higher linearity and thus chosen for better accuracy.

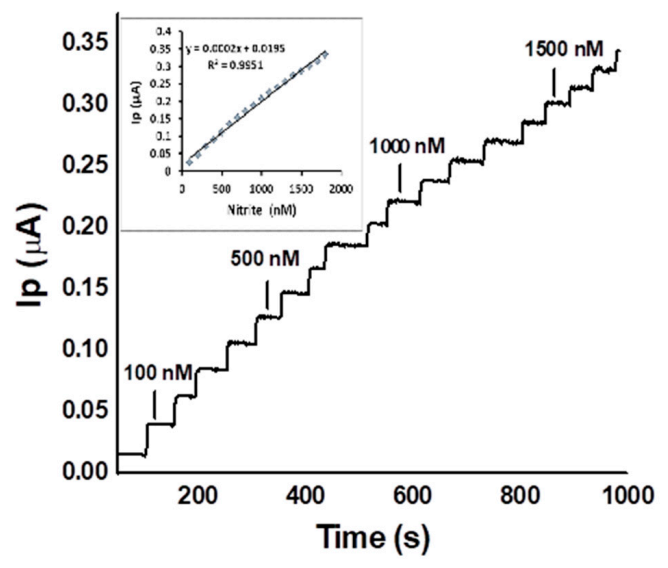

Figure 8. Amperometric (current vs. time) calibration curve recorded at applied potential of $1.0 \mathrm{~V}$ for nitrite detection in the range 100-1500 nM with inset showing the respective linear plot.

On the basis of the obtained results, it is clearly established that the performance of the nitrite sensor developed in this work has better sensitivity than that reported earlier [22] where the LOD value of $360 \mathrm{nM}$ has been described for nitrite.

\subsubsection{Interference Effect}

To investigate the selectivity of the developed Px-CuO based nitrite sensor, its response in a $1 \mu \mathrm{M}$ solution of nitrite ions was investigated at an applied potential value of $1.0 \mathrm{~V}$ in the presence of 10 -fold higher concentrations $(10 \mu \mathrm{M}$ each) of possibly interfering anions present in water $[3,18]$ such as nitrate, sulfate, carbonate, bicarbonate, chloride, ammonia (as $\left.\mathrm{NH}_{4} \mathrm{OH}\right)$, and acetate as shown in Figure 9.

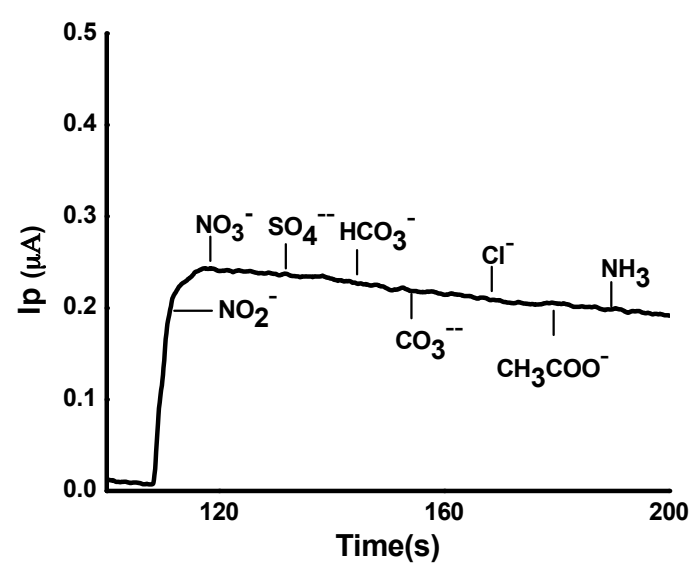

Figure 9. Amperogram showing the interference effect of 10-fold higher concentrations of interfering species on a $1 \mu \mathrm{M}$ nitrite solution. 
The interference from all anions was non-significant, which indicates that the developed Px-CuO NSs based sensor is highly selective for nitrite ions and thus can efficiently work in various matrices.

\subsection{Figures of Merit}

In order to show the positive aspects of the currently developed nitrite sensor with respect to previously designed sensors based on various nanostructured materials, Table 1 lists useful data related to several sensitive nitrite sensors. It is evident from these data that the most sensitive nitrite sensor among those listed is the one reported by Haldorai et al. [25] with an LOD of 1.4 nM. However, from a working range point of view, our Px-CuO-GCE based sensor also performs better in view of detecting concentrations of nitrite lower than those previously reported. Moreover, most of the listed nitrite sensors have been fabricated using complex and expensive materials thereby limiting their utility in economical nitrite sensing. In view of these limitations, it can be concluded that the currently developed Px-CuO NSs based nitrite sensor is comparatively better in terms of its simplicity, higher selectivity, extreme sensitivity, and highly cost-effective nature.

Table 1. Comparative data for nitrite detection using electrodes modified with different materials.

\begin{tabular}{lccc}
\hline \multicolumn{1}{c}{ Material on Electrode } & Linear Range (nM) & LOD (nM) & Reference \\
\hline Poly(vinylferrocenium)/multi-walled carbon nanotubes & $1000-400,000$ & 100 & {$[1]$} \\
Graphite-supported Pd nanoparticles & $300-50,700$ & 71 & {$[3]$} \\
Reduced graphene oxide $/ \mathrm{Co}_{3} \mathrm{O}_{4}$ nanospindle & $1000-380,000$ & 140 & {$[18]$} \\
$\mathrm{Fe}_{3} \mathrm{O}_{4}$ nanospheres on $\mathrm{MoS}_{2}$ nanoflake & $1000-2,630,000$ & 500 & {$[20]$} \\
Hexamethylenetetramine-based flower-like $\mathrm{CuO}$ & $1000-91,500$ & 360 & {$[22]$} \\
Cytochrome c immobilized on TiN & $1000-2,000,000$ & 1.4 & {$[25]$} \\
nanoparticles-decorated multi-walled carbon nanotubes & $1000-8,100,000$ & 330 & {$[26]$} \\
$\mathrm{CuS}$ supported on multiwall carbon nanotubes & $100-1800$ & 12 & This work \\
Px-CuO NSs & \\
\hline
\end{tabular}

\subsection{Application of the Developed Sensor for Nitrite Detection in Real Water Samples}

Table 2 displays the data collected for detection of nitrite in three real water samples-namely, river water, mineral water, and tap water. Each sample was spiked thrice with the indicated nitrite concentration using a protocol similar to the one used for the standard solutions. In this case, phosphate buffer was used for each type of water sample and amperometric runs were carried out just like for the standard nitrite solution. The results are shown in Table 2. A recovery range of $99.7-100.7 \%$ reveals the good performance of the Px-CuO NSs based GCE as nitrite sensor.

Table 2. Detection of nitrite in real water samples via Px-CuO NSs based sensor.

\begin{tabular}{cccc}
\hline Sample Type & Nitrite Added (nM) & Nitrite Recovered (nM) & Recovery (\%) $^{\mathbf{1}}$ \\
\hline Mineral water & 800 & $802.5 \pm 3.1$ & 100.3 \\
Tap water & 600 & $598.4 \pm 1.9$ & 99.7 \\
River water & 400 & $402.8 \pm 2.4$ & 100.7 \\
\hline
\end{tabular}

${ }^{1}$ The \pm values are the standard deviations of the 3 replications.

\section{Experimental Section}

\subsection{Chemical and Reagents}

Ammonia (33\%), copper chloride, piroxicam, sodium hydroxide, ascorbic acid, sodium borate, and sodium sulphite were obtained from Sigma-Aldrich Chemicals, Karachi, Pakistan; sodium nitrite, acetone, methanol, ethanol, hydrazine, monosodium phosphate, disodium phosphate, and phosphoric acid were purchased from E. Merck. Piroxicam was dissolved in ethanol before its use. Sodium nitrite was dissolved in deionized water and then mixed with the required quantity of phosphate buffer. 


\subsection{Synthesis of Piroxicam-Based $\mathrm{CuO}$ Nanostructures (Px-CuO NSs) via a Hydrothermal Method}

$\mathrm{Px}-\mathrm{CuO}$ NSs were prepared via a hydrothermal protocol as follows: $5 \mathrm{~mL} 0.1 \mathrm{M}$ copper chloride was mixed with $1.0 \mathrm{~g}$ piroxicam (dissolved in $5 \mathrm{~mL}$ ethanol) and the volume was made up to $90 \mathrm{~mL}$ with deionized water. The resulting mixture was stirred for $15 \mathrm{~min}$ to obtain complete homogenization. Then, $5 \mathrm{~mL}$ of $33 \%$ ammonia solution was added and the final volume was made up to $100 \mathrm{~mL}$ with deionized water in a 250-mL beaker. Finally, the beaker was tightly wrapped with aluminum foil and placed in a preheated oven at $95^{\circ} \mathrm{C}$ for $4 \mathrm{~h}$. After this period, the final product was cooled to room temperature, filtered through Whatman 41 , quantitative filter paper (having $125 \mathrm{~mm}$ diameter), washed several times with deionized water to remove the unreacted species, and dried at room temperature. The prepared $\mathrm{CuO}$ NSs were then characterized using scanning electron microscopy (SEM) and X-ray diffraction $(\mathrm{XRD})$.

\subsection{Construction of the Px-CuO NSs Sensor and Its Application for Nitrite Detection}

The GCE was thoroughly washed and cleaned according to a previously described protocol [12]. The GCE was polished simultaneously with 0.3 and 0.05 -micron alumina paste, sonicated for $5 \mathrm{~min}$ in pure acetone and deionized water, and dried under pure nitrogen gas. The prepared GCE was used as such and a similar one was modified with Px-CuO NSs and employed for all the electrochemical investigations. The Px-CuO NS-modified GCE was prepared by putting a $5-\mu \mathrm{L}$ drop of a Px-CuO NSs solution (prepared by dissolving $2 \mathrm{mg}$ of NSs in $1 \mathrm{~mL}$ methanol) and dried. This GCE was used as the nitrite sensor. Phosphate buffer (pH 7.0) was used as the supporting electrolyte in a cell having calomel as reference electrode, platinum wire as a counter electrode, and bare GCE or Px-CuO NSs modified GCE as a working electrode. During CV, a potential range of 0.0-1.2 V was applied while for amperometry, the applied potential was kept constant at $1.1 \mathrm{~V}$.

\subsection{Application of the Sensor to Real Samples}

The Px-CuO NSs based GCE was employed as a nitrite sensor for detection of nitrites in real water samples-such as mineral water, tap water, and river water-following the same protocol as the one adopted for the standard solution using a standard addition method.

\subsection{Instruments}

Morphological information of Px-CuO NSs was obtained with the help of a SEM instrument model JSM 6380 from Jeol, Tokyo, Japan. Crystalline patterns were investigated using XRD Instrument model D-8 obtained from Bruker Company, Billerica, MA, USA. All electrochemical investigations were carried out using the electrochemical workstation potentiostat model $760 \mathrm{D}$ from CH Instruments, Austin, TX, USA.

\section{Conclusions}

$\mathrm{Px}-\mathrm{CuO}$ NSs have been synthesized via a one-pot procedure based on hydrothermal precipitation with ammoniacal solution. The resulting NSs have a porous rose-petal-like morphology together with dotted particles, giving rise to the high catalytic nature of the synthesized material. The study reveals that the fabricated Px-CuO NS-based GCE is highly sensitive and selective, showing extremely enhanced peak current signals for nitrites even in the presence of several anions commonly found in real water samples. The fabricated nitrite sensor was applied for detection of nitrite ions in various water samples and a good recovery range was obtained.

Acknowledgments: We extend our sincere appreciation to the Deanship of Scientific Research at King Saud University for funding this project through Research Group (RG 236). 
Author Contributions: Ayman Nafady and Sirjuddin designed the project. Ali Alsalme, Munazza Arain and Ayman Nafady conducted the experimental work and most of the characterizations. Ali Alsalme and Munazza Arain initiated the drafting of the manuscript. Ayman Nafady and Sirajuddin provided scientific guidance for successful completion of the project and put the manuscript to the submitted form. All authors read and approved the final version of the manuscript.

Conflicts of Interest: The authors declare no conflict of interest.

\section{References}

1. Kuralay, F.; Dumangöz, M.; Tunç, S. Polymer/carbon nanotubes coated graphite surfaces for highly sensitive nitrite detection. Talanta 2015, 144, 1133-1138. [CrossRef] [PubMed]

2. Wang, Q.; Ma, S.; Huang, H.; Cao, A.; Li, M.; He, L. Highly sensitive and selective spectrofluorimetric determination of nitrite in food products with a novel fluorogenic probe. Food Control 2016, 63, 117-121. [CrossRef]

3. Yang, J.H.; Yang, H.; Liu, S.; Mao, L. Microwave-assisted synthesis graphite-supported Pd nanoparticles for detection of nitrite. Sens. Actuators B-Chem. 2015, 220, 652-658. [CrossRef]

4. Lijinsky, W.; Epstein, S.S. Nitrosamines as environmental carcinogens. Nature 1970, 225, 21-23. [CrossRef] [PubMed]

5. Pelletier, M.M.; Kleinbongard, P.; Ringwood, L.; Hito, R.; Hunter, C.J.; Schechter, A.N.; Gladwin, M.T.; Dejam, A. The measurement of blood and plasma nitrite by chemiluminescence: Pitfalls and solutions. Free Radic. Biol. Med. 2016, 41, 541-548. [CrossRef] [PubMed]

6. Betta, F.D.; Vitali, L.; Fett, R.; Costa, A.C.O. Development and validation of a sub-minute capillary zone electrophoresis method for determination of nitrate and nitrite in baby foods. Talanta 2014, 122, $23-29$. [CrossRef] [PubMed]

7. Niedzielski, P.; Kurzyca, I.; Siepak, J. A new tool for inorganic nitrogen speciation study: Simultaneous determination of ammonium ion, nitrite and nitrate by ion chromatography with post-column ammonium derivatization by Nessler reagent and diode-array detection in rain water samples. Anal. Chim. Acta 2006, 577, 220-224. [CrossRef] [PubMed]

8. Canbay, E.; Sahin, B.; Kiran, M.; Akyilmaz, E. MWCNT-cysteamine-nafion modified gold electrode based on myoglobin for determination of hydrogen peroxide and nitrite. Bioelectrochemistry 2015, 101, 126-131. [CrossRef] [PubMed]

9. Shaikh, T.; Nafady, A.; Talpur, F.N.; Sirajuddin; Agheem, M.H.; Shah, M.R.; Sherazi, S.T.H.; Soomro, R.A.; Siddiqui, S. Tranexamic acid derived gold nanoparticles modified glassy carbon electrode as sensitive sensor for determination of nalbuphine. Sens. Actuators B-Chem. 2015, 211, 359-369. [CrossRef]

10. Hassan, S.S.; Nafady, A.; Sirajuddin; Solangi, A.R.; Kalhoro, M.S.; Abro, M.I.; Sherazi, S.T.H. Ultra-trace level electrochemical sensor for methylene blue dye based on nafion stabilized ibuprofen derived gold nanoparticles. Sens. Actuators B-Chem. 2015, 208, 320-326. [CrossRef]

11. Soomro, R.A.; Hallam, K.R.; Ibupoto, Z.H.; Tahira, A.; Sherazi, S.T.H.; Sirajuddin; Jawaid, S.; Willander, M. Glutaric acid assisted fabrication of $\mathrm{CuO}$ nanostructures and their application in development of highly sensitive electrochemical sensor system for carbamates. Electroanalysis 2016, 28, 1634-1640. [CrossRef]

12. Arain, M.; Nafady, A.; Sirajuddin; Ibupoto, Z.H.; Sherazi, S.T.H.; Shaikh, T.; Khan, H.; Alsalme, A.; Niaz, A.; Willander, M. Simpler and highly sensitive enzyme-free sensing of urea via NiO nanostructures modified electrode. RSC Adv. 2016, 6, 39001-39006. [CrossRef]

13. Choi, K.I.; Kim, H.R.; Kim, K.M.; Liu, D.; Cao, G.; Lee, J.H. $\mathrm{C}_{2} \mathrm{H}_{5} \mathrm{OH}$ sensing characteristics of various $\mathrm{Co}_{3} \mathrm{O}_{4}$ nanostructures prepared by solvothermal reaction. Sens. Actuators B-Chem. 2010, 146, 183-189. [CrossRef]

14. Ayesh, A.I.; Abu-Hani, A.F.S.; Mahmoud, S.T.; Haik, Y. Selective $\mathrm{H}_{2} \mathrm{~S}$ sensor based on $\mathrm{CuO}$ nanoparticles embedded in organic membranes. Sens. Actuators B-Chem. 2016, 231, 593-600. [CrossRef]

15. Reddy, S.; Swamy, B.E.K.; Jayadevappa, H. CuO nanoparticle sensor for the electrochemical determination of dopamine. Electrochim. Acta 2012, 61, 78-86. [CrossRef]

16. Soomro, R.A.; Hallam, K.R.; Ibupoto, Z.H.; Tahira, A.; Sherazi, S.T.H.; Sirajuddin; Memon, S.S.; Willander, M. Amino acid assisted growth of $\mathrm{CuO}$ nanostructures and their potential application in electrochemical sensing of organophosphate pesticide. Electrochim. Acta 2016, 190, 972-979. [CrossRef] 
17. Hyeonjeong, H.; Hyojin, K.; Dojin, K. Fabrication and characterization of CuO nanoparticles/ZnO nanorods heterojunction structure for room temperature NO gas sensor application. J. Nanosci. Nanotechnol. 2016, 11, 11608-11612.

18. Haldorai, Y.; Kim, J.Y.; Vilian, A.T.E.; Heo, N.S.; Huh, Y.S.; Han, Y.K. An enzyme-free electrochemical sensor based on reduced graphene oxide $/ \mathrm{Co}_{3} \mathrm{O}_{4}$ nanospindle composite for sensitive detection of nitrite. Sens. Actuators B Chem. 2016, 227, 92-99. [CrossRef]

19. Salimi, A.; Hallaj, R.; Mamkhezri, H.; Hosaini, S.M.T. Electrochemical properties and electrocatalytic activity of FAD immobilized onto cobalt oxide nanoparticles: Application to nitrite detection. J. Electroanal. Chem. 2008, 619-620, 31-38. [CrossRef]

20. Zhang, Y.; Chen, P.; Wen, F.; Yuan, B.; Wang, $\mathrm{H}$. $\mathrm{Fe}_{3} \mathrm{O}_{4}$ nanospheres on $\mathrm{MoS}_{2}$ nanoflake: Electrocatalysis and detection of $\mathrm{Cr}(\mathrm{VI})$ and nitrite. J. Electroanal. Chem. 2016, 761, 14-20. [CrossRef]

21. Radhakrishnan, S.; Krishnamoorthy, K.; Sekar, C.; Wilson, J.; Kim, S.J. A highly sensitive electrochemical sensor for nitrite detection based on $\mathrm{Fe}_{2} \mathrm{O}_{3}$ nanoparticles decorated reduced graphene oxide nanosheets. Appl. Catal. B Environ. 2014, 148-149, 22-28. [CrossRef]

22. Zhang, L.; Yuan, F.; Zhang, X.; Yang, L. Facile synthesis of flower like copper oxide and their application to hydrogen peroxide and nitrite sensing. Chem. Cent. J. 2011, 5, 1-9. [CrossRef] [PubMed]

23. Fotouhi, L.; Fatollahzadeh, M.; Heravi, M.M. Electrochemical Behavior and Voltammetric determination of sulfaguanidine at a glassy carbon electrode modified with a multi-walled carbon nanotube. Int. J. Electrochem. Sci. 2012, 7, 3919-3928.

24. Soomro, R.A.; Nafady, A.; Sirajuddin; Memon, N.; Sherazi, T.H.; Kalwar, N.H. L-cysteine protected copper nanoparticles as colorimetric sensor for mercuric ions. Talanta 2014, 130, 415-422. [CrossRef] [PubMed]

25. Haldorai, Y.; Hwang, S.K.; Gopalan, A.I.; Huh, Y.S.; Han, Y.K.; Voit, W.; Anand, G.S.; Lee, K.P. Direct electrochemistry of cytochrome c immobilized on titanium nitride/multi-walled carbon nanotube composite for amperometric nitrite biosensor. Biosens. Bioelectron. 2016, 79, 543-552. [CrossRef] [PubMed]

26. Zhang, S.; Li, B.; Sheng, Q.; Zheng, J. Electrochemical sensor for sensitive determination of nitrite based on the CuS-MWCNT nanocomposites. J. Electroanal. Chem. 2016, 769, 118-123. [CrossRef]

(C) 2018 by the authors. Licensee MDPI, Basel, Switzerland. This article is an open access article distributed under the terms and conditions of the Creative Commons Attribution (CC BY) license (http:/ / creativecommons.org/licenses/by/4.0/). 